\title{
Operational mapping of the land cover of the forested area of Canada with Landsat data: EOSD land cover program
}

\author{
by M.A. Wulder ${ }^{1,2}$, J.A. Dechka ${ }^{1}$, M.A. Gillis, ${ }^{1}$, J.E. Luther ${ }^{3}$, R.J. Hall ${ }^{4}$,
}

A. Beaudoin ${ }^{5}$ and S.E. Franklin 6

\begin{abstract}
A priority of the Canadian Forest Service and Canadian Space Agency joint project, Earth Observation for Sustainable Development of Forests (EOSD), is the production of a land cover map of the forested area of Canada based upon Landsat data. The land cover will be produced through a partnership of federal, provincial and territorial governments, universities, and industry. The short-term goal of EOSD is to complete a land cover map representing year 2000 forested area conditions by early 2006. Over the longer term, EOSD will aim to produce land cover products to capture changes in forest conditions over time to support national and international reporting requirements. The forested area of Canada represents approximately half of Canada's landmass, requiring over 450 scenes for complete coverage (with overlap minimized). EOSD is working with provincial and territorial mapping agencies that have on-going land cover mapping programs to optimize production capacity. It is envisioned that the combined output of EOSD and provincial and territorial land cover mapping programs will be integrated with maps developed by other sectors and agencies (such as agriculture) to produce a complete representation of the land cover of Canada. Large-area land cover mapping using remote sensing is a relatively new phenomenon. Advances in data storage capabilities, computing power, and increases in the affordability of data have allowed for large-area projects to be undertaken in ways previously not possible. The manner in which a large-area mapping project is approached is related to a number of factors including the spatial extent of the area of interest, the spatial resolution of the selected sensor, and the products which are to be generated. In this communication we report on the strategy, methods, and status of the EOSD land cover mapping program of the forested area of Canada.
\end{abstract}

Key words: Canada, land cover, forest inventory, EOSD, Landsat, unsupervised classification, NFI

Une priorité du projet conjoint du Service canadien des forêts et de l'Agence spatiale canadienne, Observation de la Terre pour le développement durable des forêts (OTDD), est la production d'une carte de la productivité du territoire pour le territoire forestier du Canada au moyen des données Landsat. La productivité du territoire sera déterminée en fonction d'un partenariat des gouvernements fédéral, provinciaux et territoriaux, des universités et de l'industrie. L'objectif à court terme de l'OTDD est de compléter une carte de la productivité du territoire en fonction de la couverture terrestre du territoire boisé en 2000 d'ici le début de 2006 . À long terme, l'OTDD visera à produire des informations sur la couverture terrestre afin de saisir les modifications des conditions forestières en fonction du temps pour faire rapport sur la scène nationale et internationale. Le territoire forestier du Canada représente environ la moitié du territoire terrestre du Canada, nécessitant plus de 450 images pour obtenir une couverture complète (avec un recouvrement minimal). L'OTDD collabore avec les agences provinciales et territoriales de cartographie qui ont des programmes continus de cartographie de la couverture terrestre afin d'optimiser la capacité de production. On envisage que la production combinée de l'OTDD et des programmes provinciaux et territoriaux de cartographie de la couverture terrestre sera intégrée aux cartes élaborées par d'autres secteurs et agences (comme en agriculture) pour produire une représentation complète de la couverture terrestre du Canada. La cartographie de la couverture terrestre sur une grande superficie au moyen de la télédétection constitue un phénomène relativement nouveau. Les progrès au niveau des capacités d'entreposage des données, de puissance informatique et les coûts de plus en plus abordables des données ont permis la mise en marche de projets sur de grandes superficies qui auraient été autrement impossibles. L'approche retenue pour un projet de cartographie de grandes superficies repose sur le nombre de facteurs dont l'étendue spatiale du territoire sous étude, la résolution spatiale du télémètre choisi et les produits qui seront générés. Dans cet article, nous faisons état de la stratégie, des méthodes et du bilan du programme de cartographie de la couverture terrestre de l'OTDD pour le territoire forestier du Canada.

Mots clés: Canada, couverture terrestre, inventaire forestier, OTDD, Landsat, classification non supervisée, IFN

\section{Introduction}

There is an increasing demand for the mapping and monitoring of land cover in response to environmental information needs (Cihlar 2000), and concerns about the sustainability of our land resources at regional to global scales (De Bruin 2000). Countries that have signed onto agreements that include the Kyoto Protocol (United Nations Framework Convention on Climate Change 1997) and the Convention on Biological Diversity (United Nations Environment Programme 1992) have responsibilities to perform timely and accurate reporting of environmental sustainability such as the criteria and indicators that were developed in Canada (Canadian Council of Forest Ministers 2000, Hall 2001). Land cover mapping is often the process for determining the current composition and distribution of land cover that is subsequently used as the basis for assessing change in the future. These reporting obligations are not a particularly onerous task for many jurisdictions; however, some countries, provinces, and states are of such a large size that mapping and monitoring is logistically difficult. Increasingly, remote sensing is being used as a timely and valuable data source for land cover mapping, (Cihlar 2000, Franklin and Wulder 2002).

\footnotetext{
${ }^{1}$ Canadian Forest Service (Pacific Forestry Centre), Natural Resources Canada, Victoria, British Columbia.

${ }^{2}$ Corresponding author: 506 West Burnside Road, Victoria, B.C. V8Z 1M5. E-mail: mwulder@nrcan.gc.ca

${ }^{3}$ Canadian Forest Service (Atlantic Forestry Centre), Natural Resources Canada, Corner Brook, Newfoundland and Labrador.

${ }^{4}$ Canadian Forest Service (Northern Forestry Centre), Natural Resources Canada, Edmonton, Alberta.

${ }^{5}$ Canadian Forest Service (Laurentian Forestry Centre), Natural Resources Canada, Quebec City, Quebec.

${ }^{6}$ Department of Geography, University of Saskatchewan, Saskatoon, Saskatchewan.
} 
Regions (Homer et al. 1997, Huang et al. 2003), nations (Loveland et al. 1991, Fuller et al. 1994, Cihlar, et al. 2003), continents (Stone et al. 1994), and the globe (Belward et al. 1999, Hansen et al. 2000, Loveland et al. 2000) have been mapped at various spatial resolutions at a range of satellite data inputs. While a multitude of methods for mapping land cover over large areas have been reported, unsupervised classification approaches are most commonly employed (Franklin and Wulder 2002). An overview of the status and research priorities for large-area mapping with satellites can be found in Cihlar (2000) and a summary of large-area land cover mapping projects may be found in Franklin and Wulder (2002).

Forests occur over a wide range of ecosystems and their functional roles are critical to Canada from social, cultural and economic perspectives (Natural Resources Canada 2000). As a result, the monitoring of Canada's forests is required for meeting national responsibilities and for participation in international programs. To assist in forest monitoring, the Earth Observation for Sustainable Development of Forests (EOSD) program has been initiated (Wood et al. 2002). As a joint program of the Canadian Forest Service (CFS) and the Canadian Space Agency, EOSD is designed to provide, over the long term and using space-based earth observation data, products for the National Forest Inventory (Gillis 2001), forest carbon accounting (Apps et al. 1999), and monitoring of sustainable development (Wood et al. 2002). Utilising Landsat imagery as a source for mapping the land cover of the forested areas of Canada will provide data with a known vintage and broad areal coverage to generate information about the state and distribution of Canada's forests.

\section{Background}

Forest land cover mapping programs in Canada

In Canada, provinces and territories are responsible for the stewardship of the natural resources within their administrative borders. Provincial forest inventory mapping programs follow standards and definitions specific to their jurisdictions, resulting in a need for harmonization when national summaries are desired. The CFS has worked with provincial and territorial agencies to develop a National Forest Inventory (NFI) that allows for standardisation of forest inventory standards, definitions, and measurement protocols. The NFI is based upon a systematic sampling of a minimum of $1 \%$ of Canada's territory utilising a $20 \times 20 \mathrm{~km}$ grid with $2 \times 2 \mathrm{~km}$ photo plots at the grid vertices (additional details and description available in Gillis (2001)). EOSD is working closely with the NFI to ensure harmonization of standards and definitions to allow for a multi-source approach to characterising Canada's forests (Wulder et al. 2003). EOSD land cover is viewed as a primary source of NFI data for Canada's north.

The planned mapping approach is based upon using proven methods. This approach is intended to ensure delivery over the short production timelines identified. Initial methods have been identified and implemented and will be built upon and improved in an incremental fashion for future mapping iterations. To date, some key milestones are the development of a classification legend (Wulder and Nelson 2001) and an approach for addressing image radiometry (Peddle et al. 2003). We have also reviewed international initiatives and methods (Franklin and Wulder 2002), that contributed to our own methods development and the compilation of an implemen- tation manual (Wulder et al. 2001a). Basic image processing, acquisition, and rationale issues are covered in this initial version. As a result of development and testing of identified methods on nationally representative pilot regions, a second version of the methods manual was developed (Wulder et al. 2002a).

The initial goal of EOSD is to produce a national map of the forested land cover of Canada. Approximately $42 \%$ of Canada is considered forested (Lowe et al. 1996). Accounting for image overlap into non-forest areas, over $60 \%$ of the country will be mapped by EOSD. Currently, EOSD is working closely with provincial and territorial mapping agencies on a phased process to complete mapping the land cover of the forested area of Canada by early 2006. To enable the completion within this time horizon, the CFS and provincial and territorial mapping agencies have determined areas already being mapped, areas to be mapped, and areas not being mapped and have developed a plan to ensure complete coverage of the forested area of Canada. The phased implementation of EOSD will prioritize Canada's non-inventoried areas in the north for initial mapping efforts. These non-inventoried zones comprise areas that are not described to the same degree of detail as forests in the southern regions of the country. The methods and products produced by EOSD are intended to be integrated with provincial and territorial Landsat land cover map products.

\section{National forest monitoring program integration}

EOSD land cover information is a key input to the NFI and the National Forest Carbon Accounting Framework. The close integration of the NFI and EOSD programs is a mutually beneficial arrangement. Ground-plot and photo-plot information from the NFI will contribute information for cluster labelling or validation of the image classification work arising from the EOSD program and will allow for continuous testing and improvement of the classification schemes. EOSD will also provide plot information for areas where aerial photographs may not be available to generate photoplot information. In the future, EOSD products could provide the NFI with information about forest cover changes over the plots and certain spatial information about land cover in between plots. This may help identify the year in which specific events occurred (as required for Kyoto Protocol reporting) and may contribute to annual inventory updates. The potential for biases in the NFI plots can also be tested with EOSD land cover data and it can also be used to determine if the NFI sampling grid adequately captures forest characteristics across the landscape.

Products developed from the EOSD project are expected to make a significant contribution to the National Forest Carbon Accounting Framework. For example, the EOSD project is not only expected to provide forest cover maps, but other elements of the project will provide methods for estimating and mapping forest biomass using satellite and inventory data, along with techniques to identify areas affected by land use change and natural disturbance events (e.g., fire, insect, harvesting) (Wood et al. 2002).

\section{Methods}

\section{Source of imagery}

Utilising single scenes of Landsat data to produce land cover information is not uncommon. However, combining several, or even hundreds of Landsat scenes for the development of a large-area land cover map, remains relatively uncommon 
(Franklin and Wulder 2002). While many jurisdictions have undertaken large-area mapping projects with Landsat data, an increase in the level of activity can be linked to changes in United States government copyright regulations with regard to satellite data. The United States Government data-sharing and copyright policies have been altered to allow the unfettered sharing of Landsat-7 data once they are purchased. This change allowed for the affordable access to Landsat- 7 data and enabled jurisdictions responsible for the stewardship of large areas to consider satellite data as a viable data source. The Centre for Topographic Information-Sherbrooke (CTI-S), of Natural Resources Canada, is leading a national consortium to collect and orthorectify Landsat-7 ETM+ imagery of Canada representing circa year 2000 conditions. Over the next two years the CTI-S project Ortho7 will produce, with federal, provincial, and territorial partnerships, a complete set of orthorectified imagery for Canada. The orthorectified imagery will be freely available to the public via the World Wide Web. CTI$S$ Ortho 7 images will be the primary source of data supporting the EOSD project. For links and additional information on the CTI-S Ortho7 project see Wulder et al. (2002b).

\section{Radiometric pre-processing of images}

In a review of large-area mapping programs, it was noted that complete atmospheric correction procedures were rarely undertaken and that pre-processing is often limited to some form of geometric correction (Franklin and Wulder 2002). In the context of a national scale mapping effort, a top-of-atmosphere (TOA) approach to account for the influence of sun illumination on pixel radiometric response is most appropriate. This selection was based largely upon a paucity of data on atmospheric scattering and absorption at time of image acquisition to parameterize absolute correction procedures (Liang et al. 2002), and a lack of relative improvements to actual classification outcomes when more complex approaches were used (Song et al. 2001). A TOA-reflectance procedure, based upon Markham and Barker (1986) and described in Peddle et al. (2003), combined with image calibration, was the normalization approach adopted for EOSD land cover.

\section{Other processing considerations}

Some programs have mosaicked numbers of images, while others classify single scenes and have to match the edges postclassification (Franklin and Wulder 2002). In many cases, the amount of documentation on the application of mosaicking methods is limited. Other non-image-based issues also have an impact upon final classification results, such as topography, cloud cover, image year and month, and the availability and quality of training data (e.g., plot, photos, GIS data). Addressing any of these issues can result in increased costs, either through increased processing, staff time, or supplemental data collection or purchases. The goals of the classification must guide the processing needs. For instance, mosaics composed of images collected during both leaf-on and leaf-off conditions are often desired for classification, especially in deciduous and mixed forests (Dymond et al. 2002). Yet, the practical ability and costs to acquire within-year image pairs preclude such an approach for this national program. Further, the ability to collect imagery representing a single season is difficult due to the presence of cloud cover and short growing seasons. As a result, in an operational mapping program, there is a need to range out in time over seasons and years when selecting images for national mapping programs. Large-area coverages are often composed of the best image available as close as possible to the project base year. Large-area mosaics, by necessity, are an assemblage of images representing multiple years and seasons. The use of images from differing seasons can often cause greater problems for land cover mapping than using a scene from a different year but the same season because of vegetative phonological differences and their consequent effect on pixel spectral response (Wulder and Franklin 2002). When dealing with largearea coverages, mosaicking may be undertaken prior to classification on the satellite data or post-classification single scene stitching may be undertaken.

Due to reporting and carbon accounting commitments associated with the Kyoto Protocol, a 1990 Landsat-5 coverage of Canada may also be classified as part of the EOSD program. The analysis needs for classifying historic imagery are the same as when mapping current conditions, (e.g., training, ancillary, and validation data); however, additional problems exist such as: availability of data, suitability of data content and collection methods to the classification scheme, inferior data quality, insufficient or aspatial data, and unrepresentative data (e.g., only merchantable timber polygons inventoried).

\section{Image classification}

Unsupervised classification or clustering (i.e., K-means) followed by cluster merging and labelling in a manual fashion is the most widely accepted practice for large-area land cover classification (Franklin and Wulder 2002). It was adopted for the EOSD program due to the widespread application of this methodology. Hyperclustering and labelling is an established and well- understood approach for application by a wide range of users (Slaymaker et al. 1996). The hyperclustering and labelling are being applied within a hierarchical masking framework. Masks are generated by thresholding an 8-bit NDVI channel into four broad classes (to represent water, non-vegetated, coniferous, and deciduous). The masks are not intended to be exhaustive, but to provide a narrowing of the variability of digital numbers processed by the K-means classifier. To capture image spatial information, indicative of forest structural characteristics, a texture surface is computed from the $15 \times 15$ $\mathrm{m}$ spatial resolution panchromatic channel. The "intra-pixel texture" is generated by computing the variance on the panchromatic data within a $3 \times 3$ window. The variance is resampled using a bilinear algorithm to correspond to the $30-\mathrm{m}$ spatial resolution of the other multispectral channels input to the classifier. As a result of the re-sampling, we have an indication of the within-pixel variability of the Landsat optical channels. We then submit the six optical ETM+ channels and the intra-pixel texture channel to the K-means classifier (requesting 241 classes, a movement threshold of 0.1, 12 iterations, and a 50\% sample of the pixels under the mask (see Wulder et al. (2002a) for details)). Following the clustering, a process of merging similar clusters together is applied. Once the merging stage is complete the labelling of the clusters to meaningful classes takes place. Some steps in the classification process are completed through batch processing and / or specialized automation of tasks (Fig. 1). The planned mapping approach is based upon using proven, or new and tested, methods. This approach is intended to ensure delivery over the short production timelines identified. The approach will 


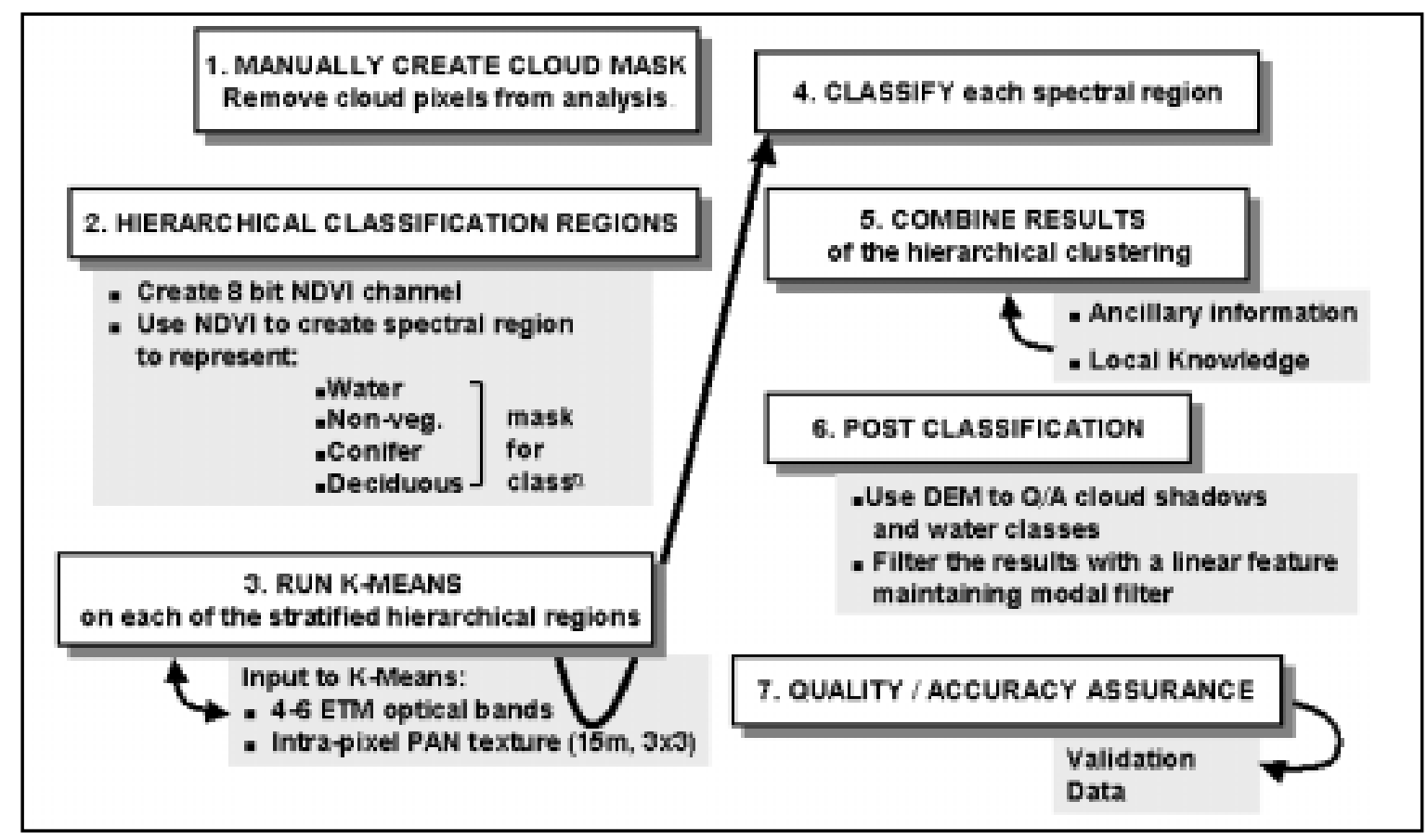

Fig. 1. Overview of EOSD Classification Methodology.

allow for providing timely and useful information for use within, and external, to Canada.

\section{Classification legend}

"Land cover" and "land use" are terms that are often used interchangeably; however, they have different meanings. Land cover results from a complex mixture of natural and anthropogenic influences and is characterized by the composition and characteristics of land surface elements (Cihlar 2000). In contrast, land use is characterised by economic uses of land and people's relationships with the environment. For EOSD we developed a classification legend based upon the hierarchical NFI land cover classification system (Wulder and Nelson 2001). The level of detail captured by the NFI is greater than that available from Landsat imagery. To integrate with the NFI and other provincial, territorial, and national programs, a legend that was compatible with the cover type level of the NFI class structure was developed (Table 1). The NFI legend was developed in co-operation with provincial and territorial forest inventory agencies through the Canadian Forest Inventory Committee. By utilizing the NFI class structure as a base, EOSD is able to standardize classified image products, and work in close association with provincial and territorial mapping agencies. For instance, we have worked with Alberta Sustainable Resource Development and the University of Alberta to ensure compatibility of classification legends and the methods used to produce the classification maps (Wulder et al. 2001b). Cross-walks between the EOSD legend and other provincial, national, and international examples are also presented in Wulder and Nelson (2001).

\section{Implementation Strategy}

EOSD land cover is presently planned to be completed by early 2006. The CTI-S Ortho7 data will be viewed as a primary source of image data for the project. The CTI-S Ortho7 project is to be completed in 2005, allowing sufficient time for the final orthorectified Landsat images to be classified prior to the EOSD deadline in 2006. Working in partnership with provincial and territorial mapping agencies, we have determined areas covered by existing or proposed programs and will work together with these agencies to ensure complete coverage. The most efficient and cost-effective approach to date has been to partner with agencies engaged in these existing land cover mapping activities in order to avoid duplication of effort, combine financial resources and technical expertise, and to develop legend translation protocols that would result in both a provincial land cover and an EOSD land cover product being produced at the same time. Clearly, the partnership approach leverages financial and in-kind support, and provides the means by which such a national product can be completed within the time frame of this program.

Over the remaining project years, more than 110 Landsat scenes per year will need to be classified to remain on schedule (Wulder and Seemann 2001). Nationally distributed production centres within CFS and the provinces and territories are established to ensure local knowledge is incorporated into the mapping where possible. Provincial and territorial partnerships are critical to the success of EOSD and the acceptance of the map products generated.

\section{Implementation Status}

Implementation of the EOSD program for the purpose of monitoring forested land began in the spring of 2002. Co-operation with federal, provincial, and territorial agencies has benefited EOSD in developing a land cover legend and has also assisted in moving towards completing the land cover map products of Canada (Fig. 2). Land cover mapping activities are cur- 
Table 1. EOSD land cover legend (based upon the NFI level 4 cover classes and level 5 density descriptors*)

\begin{tabular}{|c|c|}
\hline Class & Description \\
\hline No Data & \\
\hline Shadow & \\
\hline Cloud & \\
\hline Snow/Ice & Glacier/snow \\
\hline Rock/Rubble & Bedrock, rubble, talus, blockfield, rubbley mine spoils, or lava beds. \\
\hline Exposed Land & $\begin{array}{l}\text { River sediments, exposed soils, pond or lake sediments, reservoir margins, } \\
\text { beaches, landings, burned areas, road surfaces, mudflat sediments, cutbanks, } \\
\text { moraines, gravel pits, tailings, railway surfaces, buildings and parking, or other } \\
\text { non-vegetated surfaces. }\end{array}$ \\
\hline Water & Lakes, reservoirs, rivers, streams, or salt water. \\
\hline Shrub - Tall & $\begin{array}{l}\text { At least } 20 \% \text { ground cover which is at least one-third shrub; average shrub } \\
\text { height greater than or equal to } 2 \mathrm{~m} \text {. }\end{array}$ \\
\hline Shrub - Low & $\begin{array}{l}\text { At least } 20 \% \text { ground cover which is at least one-third shrub; average shrub } \\
\text { height less than } 2 \mathrm{~m} \text {. }\end{array}$ \\
\hline Herb & $\begin{array}{l}\text { Vascular plant without woody stem (grasses, crops, forbs, gramminoids); } \\
\text { minimum of } 20 \% \text { ground cover or one-third of total vegetation must be herb. }\end{array}$ \\
\hline Bryoids & $\begin{array}{l}\text { Bryophytes (mosses, liverworts, and hornworts) and lichen (foliose or fruticose; } \\
\text { not crustose); minimum of } 20 \% \text { ground cover or one-third of total vegetation } \\
\text { must be a bryophyte or lichen }\end{array}$ \\
\hline Wetland - Treed & $\begin{array}{l}\text { Land with a water table near/at/above soil surface for enough time to promote } \\
\text { wetland or aquatic processes; the majority of vegetation is coniferous, broadleaf, } \\
\text { or mixed wood. }\end{array}$ \\
\hline Wetland - Shrub & $\begin{array}{l}\text { Land with a water table near/at/above soil surface for enough time to promote } \\
\text { wetland or aquatic processes; the majority of vegetation is tall, low, or a mixture } \\
\text { of tall and low shrub. }\end{array}$ \\
\hline Wetland - Herb & $\begin{array}{l}\text { Land with a water table near/at/above soil surface for enough time to promote } \\
\text { wetland or aquatic processes; the majority of vegetation is herb. }\end{array}$ \\
\hline Coniferous - Dense & $\begin{array}{l}\text { Greater than } 60 \% \text { crown closure; coniferous trees are } 75 \% \text { or more of total basal } \\
\text { area. }\end{array}$ \\
\hline Coniferous - Open & $26-60 \%$ crown closure; coniferous trees are $75 \%$ or more of total basal area. \\
\hline Coniferous - Sparse & $10-25 \%$ crown closure; coniferous trees are $75 \%$ or more of total basal area. \\
\hline Broadleaf - Dense & $\begin{array}{l}\text { Greater than } 60 \% \text { crown closure; broadleaf trees are } 75 \% \text { or more of total basal } \\
\text { area. }\end{array}$ \\
\hline Broadleaf - Open & $26-60 \%$ crown closure; broadleaf trees are $75 \%$ or more of total basal area. \\
\hline Broadleaf - Sparse & $10-25 \%$ crown closure; broadleaf trees are $75 \%$ or more of total basal area. \\
\hline Mixed Wood - Dense & $\begin{array}{l}\text { Greater than } 60 \% \text { crown closure; neither coniferous nor broadleaf tree account } \\
\text { for } 75 \% \text { or more of total basal area. }\end{array}$ \\
\hline Mixed Wood - Open & $\begin{array}{l}26-60 \% \text { crown closure; neither coniferous nor broadleaf tree account for } 75 \% \text { or } \\
\text { more of total basal area. }\end{array}$ \\
\hline Mixed Wood - Sparse & $\begin{array}{l}10-25 \% \text { crown closure; neither coniferous nor broadleaf tree account for } 75 \% \text { or } \\
\text { more of total basal area. }\end{array}$ \\
\hline
\end{tabular}

* for more details see: http://www.pfc.forestry.ca/eosd/cover/eosd_report_e.html. 


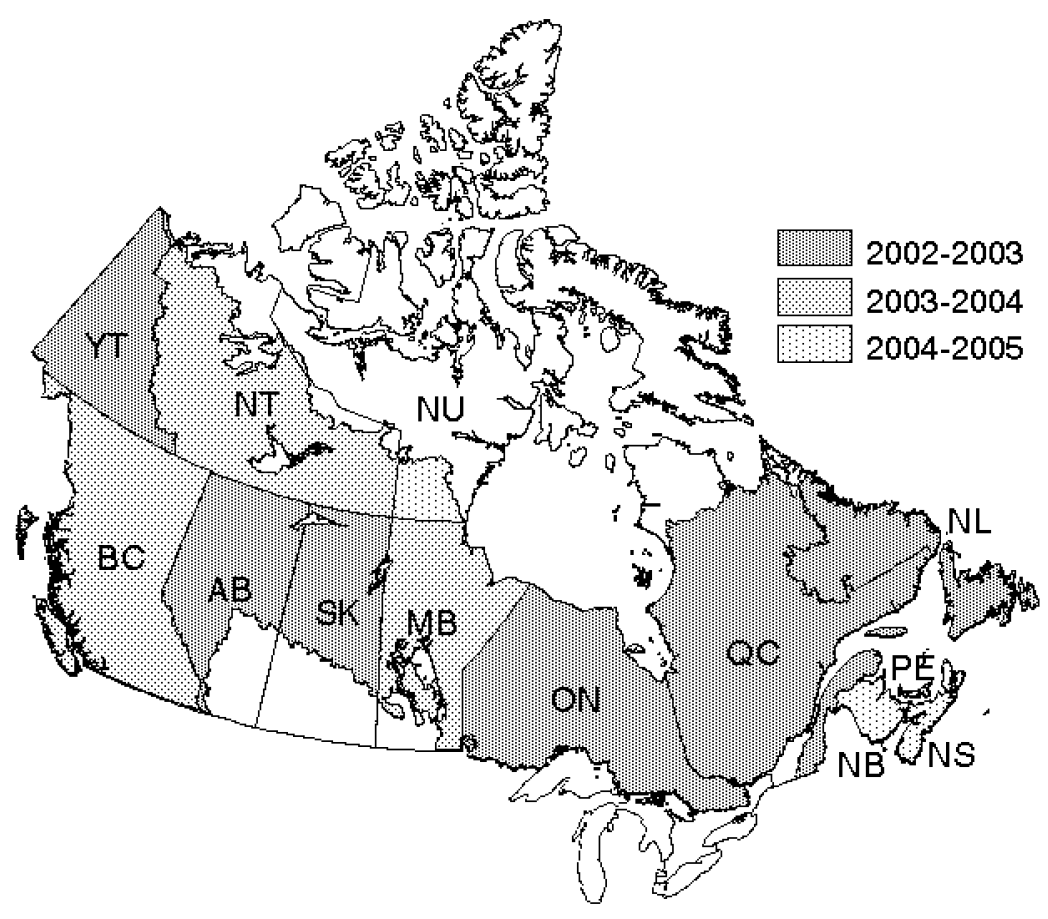

Fig. 2. Staged implementation, beginning in 2002, for the EOSD land cover mapping program.

rently in progress in Alberta, Saskatchewan, Ontario, Newfoundland and Labrador, and Yukon. Second-year implementation activities are being planned in British Columbia, Manitoba, Quebec, and Northwest Territories while New Brunswick, Nova Scotia, Nunavut, and Prince Edward Island are scheduled for implementation in the third year.

\section{Products}

EOSD land cover products are based upon the national topographic database (NTDB) national topographic survey (NTS) map sheet framework. The EOSD land cover products will be available for download on a 1:250 000 NTS map sheet basis (Fig. 3). Each map sheet represents an area of approximately $14850 \mathrm{~km}^{2}$. A total of $6151: 250000$ tiles will be required to cover the forested area of Canada. The products will be available in a Paletted GeoTiff format, with a disabled tiff world file. As a single tile may be composed of a number of images, ESRI shape files are provided to communicate source image information and actual mosaic lines (Fig. 4). Federal Geographic Data Committee (FGDC)-compliant metadata ${ }^{7}$ will also be provided with the EOSD land cover products. A data-sharing agreement will allow users to generate value-added products from EOSD classified data. Data distribution will be enabled through the World Wide Web. Users of the land cover data may utilize the data "as is" to meet information needs, or use the available data as source information to generate value-added products. As the EOSD land cover products are geo-located, integration with a variety of other spatial datasets is possible. For instance, users may integrate the land cover data with forest inventory data to enable audit, visualization, and planning.

${ }^{7}$ http://www.fgdc.gov/metadata/metadata.html
The range of external uses for the data is limitless. Internally, the primary uses for the national land cover data are the National Forest Inventory, carbon accounting, and integration with the NTDB.

\section{Conclusions}

The demand for timely environmental information about the composition, distribution and status of land cover at regional and national levels is growing at an unprecedented rate. The EOSD program was created, in part, to address some of these information needs through earth observation with Landsat-7 ETM+ data. Using established methods, the project is designed to provide timely and valuable information for use within, and external, to Canada. The current status of the project has background development complete, partnerships initiated, national production nodes active, a design for a phased implementation aiming for early 2006 completion, and a flexible product dissemination strategy. With production and partnerships underway, the $2006 \mathrm{com}-$ pletion goal is on schedule. Further work is geared towards ongoing improvements and streamlining the approaches used. Additional on-going research activities are directed towards enhancing the integration between EOSD and NFI, mosaicking protocols, and accuracy assessment procedures. The partnership efforts are intended to help produce for the first time, a comprehensive land cover map of the forested areas of Canada at a scale that provides an important baseline for future monitoring on the state of Canada's forests at the national level.

\section{Acknowledgements}

This research is enabled through funding of the Canadian Space Plan of the Canadian Space Agency and Natural Resources Canada - Canadian Forest Service. The development 


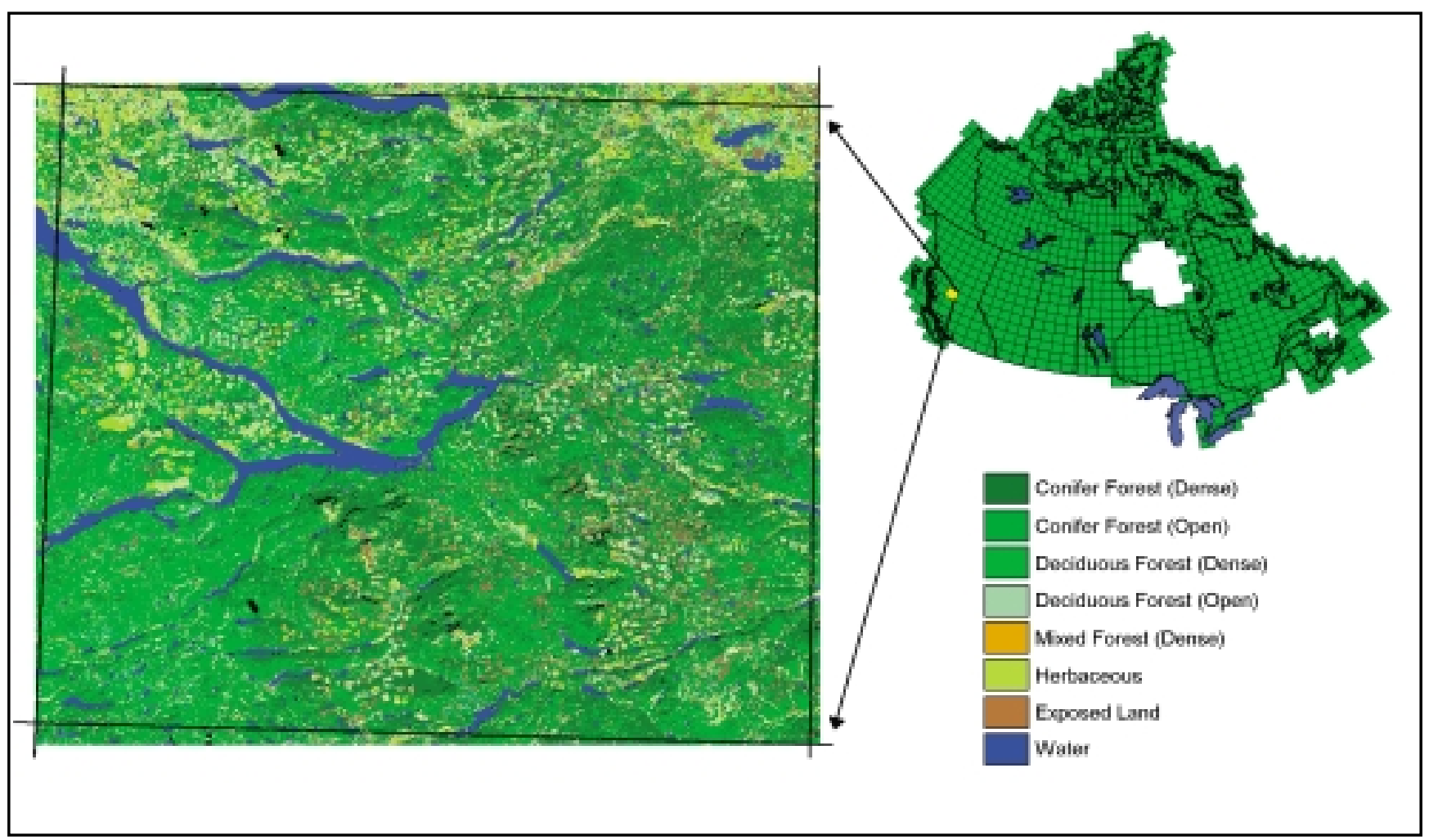

Fig. 3. Sample EOSD land cover classification product, representing same area as NTS 1:250 000 map sheet 93F (Nechako River, B.C.).

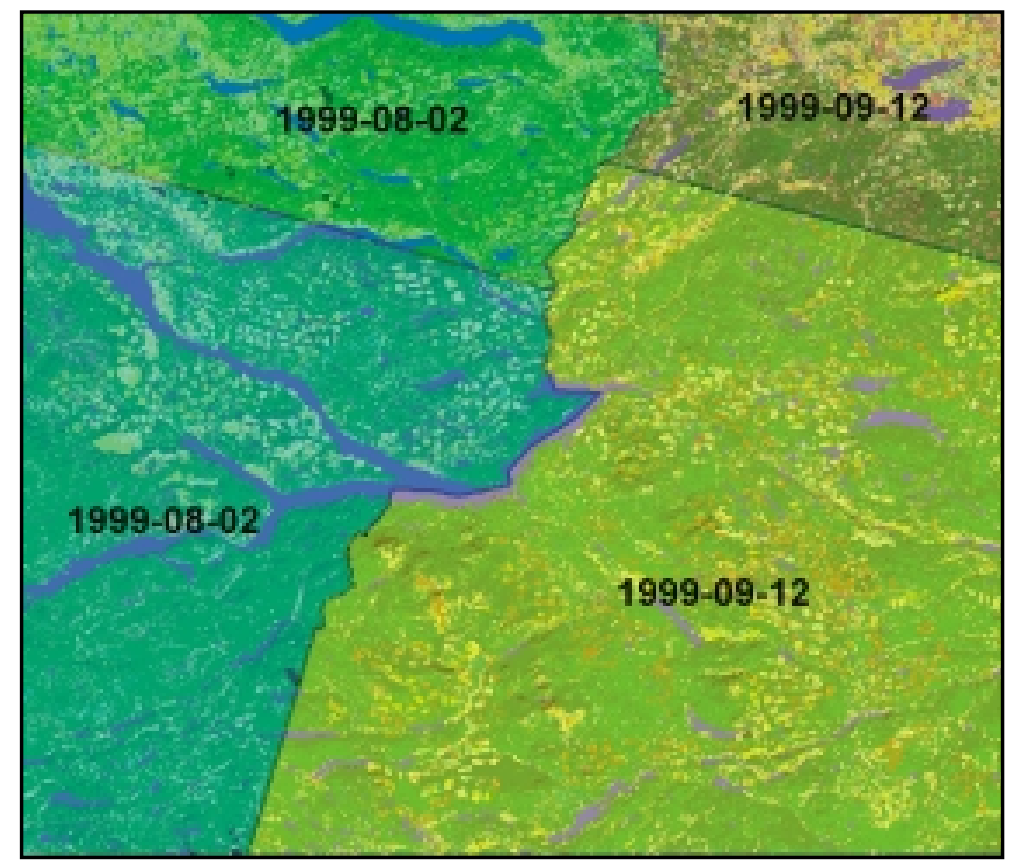

Fig. 4. Sample EOSD land cover product illustrating mosaic lines and source imagery (NTS 1:250 000 map sheet 93F (Nechako River, B.C.)

and implementation of a land cover map of the forested area of Canada is possible through the participation and partnership of a range of individuals and agencies. We acknowledge the contributions and support provided by Agriculture and AgriFoods Canada, Canada Centre for Remote Sensing, Canadian Forest Service, Canadian Wildlife Service, Department of
Indian Affairs and Northern Development and Parks Canada. The National Forest Inventory program through the Climate Change Action Fund has provided funding support. Support from Industry Canada's Executive Exchange Program has enabled the transfer of technology to the personnel in the Yukon Government. The Provinces and Territories of Canada are in 
various stages of involvement in the EOSD and/or NFI initiatives. We acknowledge the assistance, interest, and support of all these agencies from departments responsible for agriculture, conservation, forestry, geomatics, natural resources, parks and wildlife in their respective provinces. Participation of these departments is critical to the success of this initiative. Support is being provided through various organizations and initiatives including the Saskatchewan Research Council, Saskatchewan Forestry Centre, and Environment Canada's Interdepartmental Fund for Species at Risk. Ducks Unlimited and their partners have graciously provided field information to assist in the classification process. IRS-Abitibi has contributed to work in Quebec and Newfoundland and Labrador. Prince Albert Grand Council and Meadow Lake Tribal Council have supported land cover classification efforts in Saskatchewan. Additionally, researchers at the Universities of Alberta, Calgary, Toronto, and Wilfred Laurier are undertaking research activities in support of the land cover mapping initiative. The assistance of E. Arsenault, CFS-Edmonton in creating Fig. 1 is acknowledged; J. White, CFS-Pacific, is thanked for editorial assistance.

\section{References}

Apps, M.J.,W.A. Kurz, S.J. Beukema and J.S. Bhatti. 1999. Carbon budget of the Canadian forest product sector. Environmental Science and Policy 2(1): 25-41.

Belward, A.S., J.E. Estes and K.D. Kline. 1999. The IGBP-DIS global 1-km land-cover data set DISCover: A project overview. Photogrammetric Engineering and Remote Sensing 65(9): 1013-1020. Canadian Council of Forest Ministers. 2000. Criteria and Indicators of Sustainable Forest Management in Canada: National Status 2000. Natural Resources Canada, Canadian Forest Service, Ottawa, Ontario. Cihlar, J. 2000. Land cover mapping of large areas from satellites: status and research priorities. International Journal of Remote Sensing 21(6\&7): 1093-1114.

Cihlar, J., R. Latifovic, J. Beaubien, A. Trishchenko, J. Chen and G. Fedosejevs. 2003. National scale forest information extraction from coarse resolution satellite data, Part 1. Data processing and mapping land cover types. In M. Wulder and S. Franklin (eds.). Remote Sensing of Forest Environments: Concepts and Case Studies. pp. 337-357. Kluwer Academic Publishers, Dordrecht / Boston / London.

De Bruin, S. 2000. Predicting the Areal Extent of Land-Cover Types Using Classified Imagery and Geostatistics. Remote Sensing of Environment 74(3): 387-396.

Dymond, C.C., D.J. Mladenoff and V.C. Radeloff. 2002. Phenological differences in Tasseled Cap indices improve deciduous forest classification. Remote Sensing of Environment 80(3): 460-472. Franklin, S.E. and M.A. Wulder. 2002. Remote sensing methods in medium spatial resolution satellite data land cover classification of large areas. Progress in Physical Geography 26(2): 173-205.

Fuller, R., G. Groom and A. Jones. 1994. The land cover map of Great Britain: An automated classification of Landsat Thematic Mapper data. Photogrammetric Engineering and Remote Sensing 60(5): 553-562.

Gillis, M.D. 2001. Canada's national forest inventory (responding to current information needs). Environmental Monitoring and Assessment 67(1\&2): 121-129.

Hall, P.J. 2001. Criteria and indicators of sustainable forest management. Environmental Monitoring and Assessment. 67(1\&2): 109-119.

Hansen, M.C., R.S. DeFries, J.R.G. Townshend and R. Sohlberg. 2000. Global land cover classification at $1 \mathrm{~km}$ spatial resolution using a classification tree approach. International Journal of Remote Sensing 21(6\&7): 1331-1364.

Homer, C., R. Ramsey, T. Edwards Jr. and A. Falconer. 1997. Landscape cover-type modeling using a multi-scene thematic mapper mosaic. Photogrammetric Engineering \& Remote Sensing 63(1): $59-67$.
Huang, C., C. Homer and L. Yang. 2003. Regional forest land cover characterizations using medium spatial resolution satellite data. In M. Wulder and S. Franklin (eds.). Remote Sensing of Forest Environments: Concepts and Case Studies. pp. 389-410. Kluwer Academic Publishers, Dordrecht/ Boston/London.

Liang, S., H. Fang, J.T. Morisette, M. Chen, C.J. Shuey, C.L. Walthall and C.S.T. Daughtry. 2002. Atmospheric correction of Landsat ETM+ land surface imagery, Part II: Validation and applications. IEEE Transactions on Geoscience and Remote Sensing 40(12): 2736-2746.

Loveland, T.R., J. Merchant, D. Ohlen and J. Brown. 1991. Development of a land-cover characteristics database for the conterminous United States. Photogrammetric Engineering \& Remote Sensing, 57(11): 1453-1463.

Loveland, T.R., B.C. Reed, J.F. Brown, D.O. Ohlen, Z. Zhu, L. Yang and J.W. Merchant. 2000. Development of a global land cover characteristic database and IGBP DISCover from $1 \mathrm{~km}$ AVHRR data. International Journal of Remote Sensing 21(6\&7): 1303-1330.

Lowe, J., K. Power and M. Marsan. 1996. Canada's forest inventory 1991: Summary by terrestrial ecozones and ecoregions. Canadian Forest Service, Pacific Forestry Centre. Information Report BCX-364E. 56 p.

Markham, B. and J. Barker. 1986. Landsat MSS and TM post-calibration dynamic ranges, exoatmospheric reflectances and at satellite temperatures. EOSAT Landsat Technical Note 1: 3-7.

Natural Resources Canada. 2000. The State of Canada's Forests: Forests in the New Millennium. Natural Resources Canada, Canadian Forest Service, Ottawa, Ontario.

Peddle, D., P. Teillet and M. Wulder. 2003. Radiometric image processing, In M. Wulder and S. Franklin (eds.). Remote Sensing of Forest Environments: Concepts and Case Studies. pp. 181-208. Kluwer Academic Publishers, Dordrecht/ Boston/London.

Slaymaker, D., K. Jones, C. Griffin and J. Finn. 1996. Mapping deciduous forests in southern New England using aerial videography and hyperclustered multi-temporal Landsat TM imagery. In J. Scott, T. Tear and F. Davis (eds.). Gap Analysis: A Landscape Approach to Biodiversity Planning. pp. 87-101. American Society of Photogrammetry and Remote Sensing, Bethesda, MD, USA.

Song, C., C.E. Woodcock, K.C. Seto, M.P. Lenney and S.A. Macomber. 2001. Classification and change detection using Landsat TM data: When and how to correct atmospheric effects. Remote Sensing of Environment 75(2): 230-244.

Stone, T., P. Schlesinger, T. Houghton and G. Woodwell. 1994. A map of the vegetation of South America based on satellite imagery. Photogrammetric Engineering \& Remote Sensing 60(5): 541-551. United Nations Environment Programme. 1992. Convention on Biological Diversity: Convention Text. [cited 23 April 2003]. Available from: http://www.biodiv.org/convention/articles.asp

United Nations Framework Convention on Climate Change. 1997. Kyoto Protocol to the United Nations Framework Convention on Climate Change. [cited 23 April 2003]. Available from: http://unfccc.int/resource/docs/convkp/kpeng.html

Wood, J.E, M.D. Gillis, D.G. Goodenough, R.J. Hall, D.G. Leckie, J. L Luther and M. Wulder. 2002. Earth Observation for Sustainable Development of Forests (EOSD): Project Overview. In Proceedings of the 2002 IEEE International Geoscience and Remote Sensing Symposium (IGARSS 2002) and the 24th Canadian Symposium on Remote Sensing, June 24-28, 2002, Toronto, Canada. IEEE, Piscataway, New Jersey. [on CD-ROM].

Wulder, M., M. Cranny and J. Dechka. 2002a. An Illustrated Methodology for Land Cover Mapping of Forests with Landsat-7 ETM+ Data: Methods in Support of EOSD Land Cover, Version 2. Natural Resources Canada, Canadian Forest Service, Pacific Forestry Centre, Victoria, BC, Canada. Available from: http://www.pfc.forestry.ca/ eosd/cover/Methods_vers2_e.pdf 
Wulder, M. and S. Franklin. 2002. Spatial and spectral variability due to Landsat image acquisition date: The impact on image classification. In Proceedings of the 2002 IEEE International Geoscience and Remote Sensing Symposium (IGARSS 2002) and the 24th Canadian Symposium on Remote Sensing, June 24-28, 2002, Toronto, Canada. IEEE, Piscataway, New Jersey. [on CD-ROM].

Wulder, M., M. Gillis, J. Luther and A. Dyk. 2001a. Manual for Classification of Landsat Data to NFI Specifications, Natural Resources Canada, Canadian Forest, Service, Pacific Forestry Centre, Victoria, BC. Available from: http://www.pfc. forestry.ca/profiles/wulder/NFIUsersGuide.pdf

Wulder, M., W. Kurz and M. Gillis. 2003. National Level Forest Monitoring and Modeling in Canada. Progress in Planning. In Press. Wulder, M., E. Loubier and D. Richardson. 2002b. A Landsat7 ETM+ orthoimage coverage of Canada. Canadian Journal of Remote Sensing, 28(5): 667-671.
Wulder, M. and T. Nelson. 2001. EOSD Legend: Characteristics, Suitability, and Compatibility, Version 1. Natural Resources Canada, Canadian Forest Service, Pacific Forestry Centre, Victoria, BC Available from: http://www.pfc.forestry.ca/ eosd/cover/EOSD_Legend_Report.pdf

Wulder, M., G. A. Sanchez-Azofeifa, S. Hamilton and K. Dutchak. 2001b. Use of high spatial resolution satellite data as a calibration data source to aid in the cluster labelling when classifying Landsat data. In Proceedings of the 23rd Canadian Symposium on Remote Sensing, Remote Sensing in the Third Millennium: From Global to Local, August 21-24, 2001, Université Laval, Sainte-Foy, Québec. [on CD-ROM].

Wulder, M. and D. Seemann. 2001. Spatially partitioning Canada with the Landsat Worldwide Referencing System. Canadian Journal of Remote Sensing, 27(3): 225-231. 